\title{
p53 immunoreactivity in cervical intraepithelial neoplasia and non-neoplastic cervical squamous epithelium
}

\author{
M D Jeffers, J Richmond, M Farquharson, A M McNicol
}

\begin{abstract}
Aims-To determine the pattern of p53 immunoreactivity in cervical squamous epithelium and to investigate the relation between p53 immunostaining and human papillomavirus (HPV) infection.

Methods-Immunocytochemistry for p53 was performed in 65 specimens of formalin fixed, paraffin wax embedded cervical tissue using a polyclonal antibody against recombinant p53. Microwave oven heating was used for antigen retrieval. Eight normal biopsy specimens, eight cases with histological features of HPV infection, and 49 cases of cervical intraepithelial neoplasia (CIN) were examined. Thirty one cases of CIN were examined for evidence of HPV infection using in situ hybridisation with probes directed against wide spectrum HPV, HPV 16 and HPV 18.
\end{abstract}

Results-p53 immunoreactivity was seen in seven of eight $(87 \%)$ of specimens with histological features of HPV infection, five of eight (62\%) normal specimens, 13 of $22(59 \%) \mathrm{CIN}$ III, three of $14(21 \%)$ CIN II and five of $13(38 \%)$ CIN I specimens. The numbers of positive nuclei were small in cases of CIN and the location of positive nuclei within the epithelium paralleled the degree of dysplasia. Eleven of 15 (73\%) CIN specimens which were immunoreactive for p53 yielded a positive signal for HPV by in situ hybridisation. A positive signal for HPV was also seen in 10 of $16(63 \%)$ of CIN specimens in which p53 staining was absent.

Conclusions-p53 immunoreactivity can be demonstrated in a small proportion of cells in the cervical squamous epithelium in a significant proportion of cases of CIN. This immunoreactivity seems to be independent of the presence of HPV, as assessed by in situ hybridisation. p53 immunoreactivity also occurs in nonneoplastic cervical squamous epithelium with a pattern of distribution within the epithelium which differs from that seen in CIN. Antigen retrieval by microwave oven heating enhances p53 immunostaining and may result in visualisation of cellular p53 in the absence of mutation.

(F Clin Pathol 1994;47:1073-1076)
The p53 gene functions as a tumour suppressor gene encoding a 53 kilodalton nuclear phosphoprotein involved in the regulation of cell growth. ${ }^{1}$ Abnormalities of p53 are among the most common genetic abnormalities in human malignancies. ${ }^{23}$ Loss of wild-type p53 activity is associated with increasing grades of dysplasia ${ }^{45}$ and is thought, in most cases, to be a late event in neoplastic transformation, possibly associated with acquisition of invasive or metastatic potential. ${ }^{4}$ Establishing the pattern of p53 immunoreactivity in intraepithelial neoplasia is important for the understanding of tumour progression, as it may indicate whether, in a particular tissue, p53 inactivation is an early event or occurs late in neoplastic transformation, as it seems to in the colon where p53 inactivation is associated with malignant transformation in dysplastic polyps. ${ }^{4}$ Wild-type p53 protein has a short half-life (five to 20 minutes) and is not normally detectable by standard immunocytochemistry. ${ }^{8}$

Immunoreactivity for $\mathrm{p} 53$ protein has been described in a wide range of human tumours, ${ }^{4569-13}$ including carcinoma of the uterine cervix. ${ }^{1415}$ The pattern of p53 immunoreactivity in cervical intraepithelial neoplasia (CIN) and non-malignant conditions of the cervix is less clearly documented. This study was undertaken to investigate the pattern of p53 immunoreactivity in normal and premalignant cervical squamous epithelium and to explore the relation, if any, between this and the presence of human papillomavirus infection (HPV).

\section{Methods}

Sixty five specimens of formalin fixed, paraffin wax embedded cervical tissue were examined. The histological diagnosis was confirmed by review of haematoxylin and eosin stained sections. There were 49 cases of CIN (22 CIN III, 14 CIN II, 13 CIN I), eight cases showing histological features of HPV infection and eight normal biopsy specimens. Serial 4 $\mu \mathrm{m}$ thick sections were cut and mounted on slides coated with aminopropyltriethoxysilane for histopathological analysis, immunocytochemical staining, and in situ hybridisation.

Immunocytochemistry was performed using a standard labelled streptavidin method with the sheep polyclonal antibody S206-120 


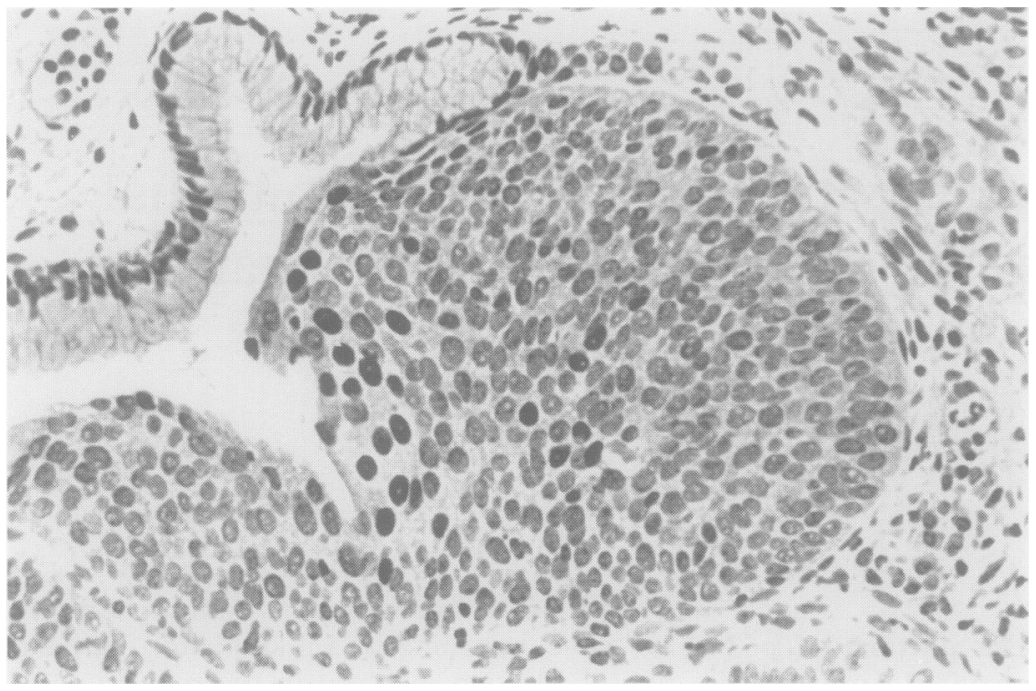

Figure 1 CIN III: nuclear p53 immunoreactivity at all levels of the dysplastic epithelium can be seen. minutes and diaminobenzidine used as chromogen. Sections were counterstained with methyl green, dehydrated, and mounted. A breast carcinoma with documented p53 mutation was used as a positive control and a negative control was performed by substituting normal sheep serum for primary antibody.

For in situ hybridisation, probes directed against wide spectrum HPV, HPV 16, and HPV 18 were used (Dako). These were supplied as double stranded DNA probes, fluorescein labelled by nick translation. In situ hybridisation was performed following the manufacturer's instructions. Briefly, sections were dewaxed and digested with $0.8 \%$ pepsin (Dako) in $0.2 \mathrm{~N}$ hydrochloric acid for $30 \mathrm{~min}$ utes at $37^{\circ} \mathrm{C}$. After washing, probe was applied to the sections and probe and target DNA were denatured by heating at $90^{\circ} \mathrm{C}$ for six minutes. Sections were transferred to $37^{\circ} \mathrm{C}$ for two hours. Non-specific hybrids were removed by a stringent wash at $48^{\circ} \mathrm{C}$ for wide spectrum HPV and at $58^{\circ} \mathrm{C}$ for HPV 16 and HPV 18. Detection was carried out using an alkaline phosphatase conjugated rabbit antibody to fluorescein isothiocyanate (FITC) (Dako) and visualised by the nitroblue tetrazolium substrate system. Slides were counterstained with $1 \%$ light green and water mounted using Glycergel (Dako). hydrogen peroxide. This was followed by five cycles of microwave oven heating in citrate buffer ( $\mathrm{pH} \mathrm{6)}$ for five minutes in each cycle, after which the slides were allowed to cool for 20 minutes. Sections were incubated in normal rabbit serum at a 1 in 5 dilution for 15 minutes and primary antibody applied at 1 in 10000 in TRIS buffered saline containing 5\% normal human serum for 30 minutes. Biotinylated rabbit anti-sheep antibody (Vector Labs) was applied at 1 in 200 in TBS containing $5 \%$ normal human serum and normal rabbit serum for 30 minutes. Washing with TBS (pH 7.6) containing $0.05 \%$ Triton$\mathrm{X}-100$ was performed between each step.

Streptavidin horseradish peroxidase (Boehringer Mannheim) was applied for 60

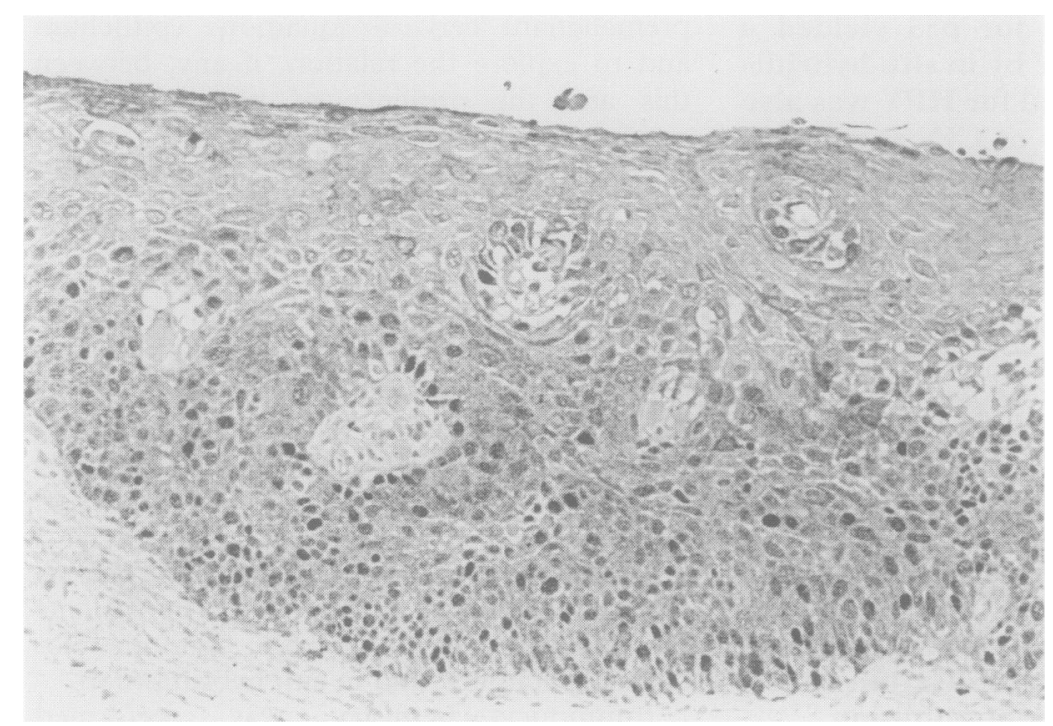

Figure 2 Squamous metaplasia: $p 53$ immunoreactivity is present, chiefly in the basal and suprabasal layers.

\section{Results}

Immunoreactivity for p53 was restricted to the epithelium and localised to the nucleus in all cases. Thirteen of $22(59 \%)$ cases of CIN III stained with immunoreactive nuclei present in all layers of the epithelium (fig 1). The numbers of positive staining nuclei were small in most cases. In eight cases the basal nuclei in adjacent non-dysplastic epithelium stained positively. Three of $14(21 \%)$ cases of CIN II and five of $13(38 \%)$ cases of CIN I showed positive staining with immunoreactive nuclei in the lower and middle layers of the epithelium in CIN II and in the basal and suprabasal layers in CIN I.

Seven of eight $(87 \cdot 5 \%)$ cases with histological features of HPV infection showed immunoreactive nuclei including one case of frank condylomatous change in which all layers of the epithelium were affected. Five of eight $(62.5 \%)$ cases of normal cervical epithelium showed immunoreactive nuclei restricted to the basal and suprabasal layers of the epithelium and chiefly localised to areas of squamous metaplasia (fig 2).

HPV in situ hybridisation in CIN

\begin{tabular}{lllll}
\hline CIN grade* & $n$ & Wide spectrum HPV & HPV 16 & HPV 18 \\
\hline I(a) & 3 & 2 & 1 & 1 \\
I(b) & 3 & 1 & 0 & 0 \\
II(a) & 3 & 3 & 1 & 1 \\
II(b) & 9 & 6 & 3 & 0 \\
III(a) & 9 & 6 & 3 & 1 \\
III(b) & 4 & 3 & 1 & 0
\end{tabular}

*(a) p53 immunoreactive; (b) p53 immunonegative. 


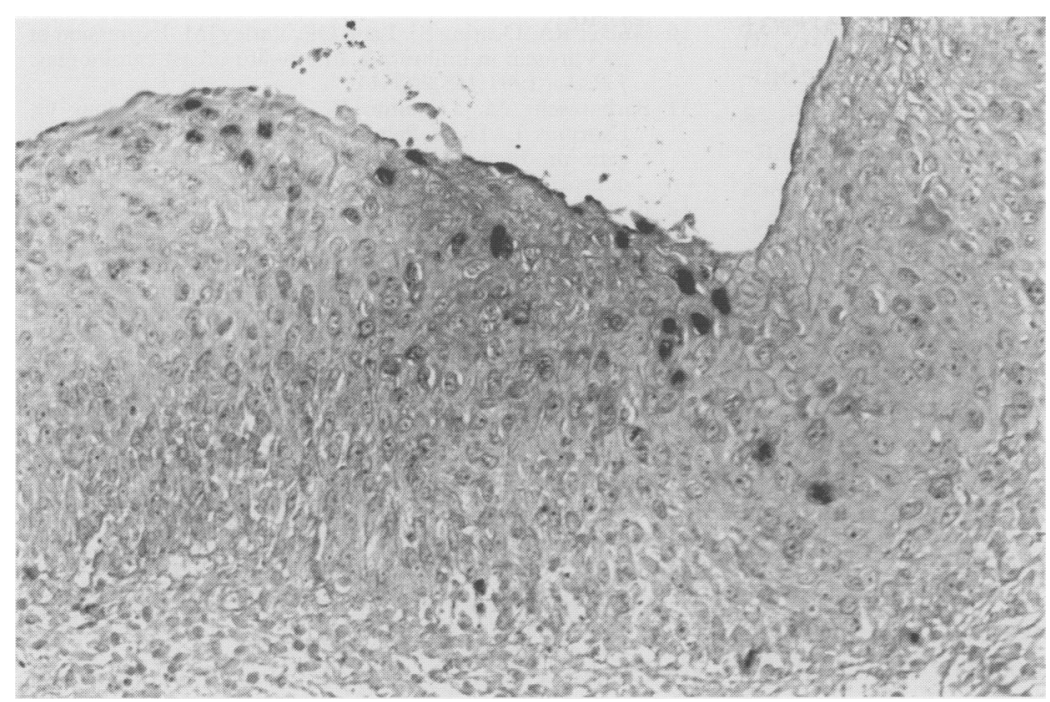

Figure 3 CIN III: positive signal for HPV 16 by in situ hybridisation.

In situ hybridisation using probes for wide spectrum HPV, HPV 16, and HPV 18 was performed on 31 cases of CIN, 15 of which showed p53 immunoreactivity and 16 of which were $\mathrm{p} 53$ immunonegative. The results are shown in the table. Eleven of 15 cases (73\%) of $\mathrm{CIN}$ which were immunoreactive for $\mathrm{p} 53$ yielded a positive signal for HPV (fig 3). Five cases were positive for HPV 16 and three for HPV 18, one case yielding a positive signal for both of these subtypes. Positive signal for wide spectrum HPV and HPV 16 was also seen in 10 of 16 and four of 16 cases, respectively, of p53 immunonegative CIN.

\section{Discussion}

Loss of wild-type p53 activity is an important event in neoplastic transformation in cervical squamous epithelium and is thought to occur by two separate mechanisms: (1) degradation of wild-type p53 protein by the E6 viral protein of HPV 16 and HPV 18; and (2) somatic mutation of the p53 gene in HPV negative cases. ${ }^{1617}$ Not all cases of cervical carcinoma are associated with p53 abnormalities, however, as indicated by reports of HPV negative cases with wild-type p53.18 On the basis of these mechanisms, clinically relevant p53 immunoreactivity would not be expected in HPV related cervical carcinoma and CIN.

In contrast to the consistent findings in invasive carcinoma, reports of p53 overexpression in squamous intraepithelial neoplasia conflict. Both positive ${ }^{19}$ and negative ${ }^{20}$ staining has been reported in dysplastic oral mucosa and positive staining correlating with grade has been demonstrated in anal intraepithelial neoplasia. ${ }^{21} 22$ In the uterine cervix p53 immunoreactivity has been described in CIN $^{1522-25}$ with the location of immunoreactive nuclei parallelling the extent of dysplasia within the epithelium, but with variation in the proportion of positive nuclei present and, in one study, ${ }^{22}$ no correlation between p53 immunoreactivity and HPV infection. Holm et al were unable, however, to demonstrate p53 immunoreactivity in CIN of any grade or in areas of condylomatous change, although they described positive staining in a small number of nuclei in one case of squamous carcinoma in situ, a condition which most pathologists would consider equivalent to CIN III. ${ }^{14}$ Our results indicate that immunocytochemically detectable p53 is expressed in most cases of high grade CIN, with the location of nuclear staining parallelling the extent of intraepithelial abnormality and that this immunoreactivity is restricted to a small number of nuclei in most cases.

Positive immunocytochemical staining for $\mathrm{p} 53$ protein is no longer considered to equate with mutation in all cases as significant "false positives" (p53 immunoreactive cells in tumours without p53 mutation) have been described. $^{7}$ p53 immunoreactivity has also been demonstrated in non-neoplastic conditions. ${ }^{26}$ This may be related to interruption of normal cellular p53 homeostasis in inflammatory or reactive conditions whereby the halflife of wild-type cellular p53 is prolonged secondary to binding to other cell proteins or to alterations in regulatory sequences. ${ }^{23} 27$ Normal cellular p53 can be detected by immunocytochemistry in certain conditions caused by DNA damage and G1 arrest. ${ }^{27}$

The sensitivity of immunocytochemistry in archival material is affected by antigen retrieval or unmasking techniques. In formalin fixed tissue many antigens are believed to be masked rather than destroyed by the fixation process and a variety of techniques, including the use of proteolytic enzymes and heating by a radiant heat source or by microwaving, enhance antigen detection. ${ }^{28-30}$ Microwaving has been shown to be reliable in p53 protein unmasking in routinely fixed material using both monoclonal ${ }^{2831}$ and polyclonal $^{28}$ antibodies, and in one study no significant difference was found between the results of staining in fixed and frozen tissue. ${ }^{31}$ Using microwave antigen retrieval we have shown extensive p53 immunoreactivity in non-neoplastic cervical epithelium, with a staining pattern similar to that described before ${ }^{15} 2223$ in which immunoreactivity is limited to the basal and immediately suprabasal layers of the squamous epithelium in areas of metaplasia, thus showing a distinctly different staining pattern from that seen in CIN.

We found evidence of HPV infection using in situ hybridisation in about three quarters of cases of CIN which is broadly in keeping with the expected number, being slightly lower than the proportion reported by Bergeron et $a l,{ }^{32}$ who used a more sensitive Southern blot technique, and similar to that of Pollanen et $a l^{25}$ and Helland $e t a l^{27}$ using in situ hybridisation. No consistent correlation between p53 immunoreactivity and the presence of HPV infection was seen but, interestingly, a proportion of HPV positive cases also showed occasional p53 immunoreactive nuclei. This is somewhat contrary to the generally held view that HPV associated cervical squamous neoplasia have wild-type p53 and so should not contain sufficient p53 for immunocytochemi- 
cal detection. This p53 immunoreactivity in HPV positive cases may be a result of stabilisation of cellular p53 by viral proteins, a mechanism which could also explain the pattern of p53 immunoreactivity seen in the cases of HPV infection without evidence of CIN. The numbers of $\mathrm{p} 53$ positive cells in CIN lesions were small in most cases. These could represent normal cells trapped within an area of intraepithelial neoplasia. Their location at all levels of the epithelium, unlike the basal and suprabasal staining seen in normal epithelium, makes this unlikely, although this abnormal distribution of normal p53 positive cells might be a reflection of the higher degree of organisation in normal epithelium compared with intraepithelial neoplasia. Alternatively, these p53 positive cells may be genuinely neoplastic in which case p53 immunoreactivity may reflect induction of p53 in transformed cells as a result of genetic instability within the neoplastic cell population. In some HPV infected cells loss of the viral genome may permit normal p53 mediated growth suppressive activity and consequent positive immunostaining.

In summary, we have shown that p53 immunoreactivity can be demonstrated in a small number of cells in CIN. Clinically relevant p53 immunoreactivity is also seen in non-neoplastic conditions in the cervix, but with a pattern different from that seen in CIN.

1 Lamb P, Crawford L. Characterisation of the human p53 gene. Mol Cell Biol 1986;6:1379-85.

2 Nigro JM, Baker SJ, Preisenger AC, Jessup JM, Hostetter R, Cleary $\mathrm{K}$, et al. Mutations in the p 53 gene occur in Cleary $\mathrm{K}$, et al. Mutations in the p53 gene occur
diverse human tumour types. Nature 1989;342:705-8.

3 Hollstein M, Sidransky D, Vogelstein B, Harris C. p53 mutations in human cancers. Science 1991;253:49-53.

4 Van den Berg FM, Tigges AJ, Schipper MEI, Den HartogJager FCA, Kroes WGM, Walboomers JMM. Expression of the nuclear oncogene p53 in colon tumours. F Pathol 1989;157:193-9.

5 Purdie CA, O'Grady J, Piris J, Wyllie AH, Bird CC. p53 expression in colorectal tumours. Am F Pathol 1991;138: 807-13.

6 Porter PL, Gown AM, Kramp SG, Coltrera MD. Widespread p53 overexpression in human malignant tumours. An immunohistochemical study using tumours. An immunohistochemical study using methacarn-fixed

7 Wynford-Thomas D. p53 in tumour pathology: can we trust immunocytochemistry? $\mathcal{f}$ Pathol 1992;166:329-30.

8 Jensen RA, Page DL. p53: the promising story continues. Hum Pathol 1993;24:455-6.

9 Caamano J, Ruggeri B, Momiki S, Zhang SY, KleinSzanto AJP. Detection of p53 in primary lung tumours and nonsmall cell lung carcinoma cell lines. Am f Pathol 1991;139:839-45.
10 Walker RA, Dearing SJ, Lane DP, Varley JM. Expression of p53 protein in infiltrating and in-situ breast carcinomas. f Pathol 1991;165:203-11.

11 Barbareschi M, Girlando S, Mauri FA, Arrigoni G, Laurinos L, Dalla Palma P, et al. Tumour suppressor gene products, proliferation and differentiation in lung neuroendocrine neoplasms. F Pathol 1992;166:343-50.

12 Barton $\mathrm{CM}$, Staddon SL, Hughes $\mathrm{CM}$, Hall PA O'Sullivan C, Kloppel G, et al. Abnormalities of the p53 tumour suppressor gene in human pancreatic cancer. $\mathrm{Br}$ tumour suppressor gene in

13 Seruca R, David L, Holm R, Nesland JM, Fangan BM, Castedo $\mathrm{S}$, et al. p53 mutations in gastric carcinomas. $\mathrm{Br}$ f Cancer 1992;65:708-10.

14 Holm R, Skomedal H, Helland A, Kristensen G, Borrensen A, Nesland J. Immunohistochemical analysis of p53 protein overexpression in normal, premalignan and malignant tissues of the cervix uteri. $\mathcal{f}$ Pathol 1993;169:21-6.

15 Bosari S, Roncalli M, Viale G, Bossi P, Coggi G. p53 immunoreactivity in inflammatory and neoplastic diseases of the uterine cervix. $\mathcal{F}$ Pathol 1993;169:425-30.

16 Scheffner M, Werness BA, Huibregtse JM, Levine AJ, Howley PM. The E6 oncoprotein encoded by human papilloma virus types 16 and 18 promotes the degradation of p53. Cell 1990;63:1129-36.

17 Crook T, Wrede D, Tidy JA, Mason WP, Evans DJ, Vousden $\mathrm{KH}$. Clonal p53 mutations in primary cervical cancer: association with human papillomavirus negative tumours. Lancet 1992;339:1070-3.

18 Busby-Earle RMC, Steel CM, Williams ARW, Cohen B, Bird CC. Papillomaviruses, p53 and cervical cancer. Lancet 1992;339:1350.

19 Gusterson BA, Anbazhagan R, Warren W, Midgely C, Lane DP, O'Hare M, et al. Expression of p53 in premalignant and malignant squamous epithelium. malignant and malign

20 Ogden GR, Kiddie RA, Lunny DP, Lane DP. Assessment of $\mathrm{p} 53$ protein expression in normal, benign and malignant oral mucosa. F Pathol 1992;166:389-94.

21 Ogunbiyi OA, Scholefield JH, Smith JHF, Polacarz SV, Rogers K, Sharp F. Immunohistochemical analysis of p53 expression in anal squamous neoplasia. $\mathcal{F}$ Clin Pathol 1993;46:507-12.

22 Walts AE, Koeffler HP, Said JW. Localization of $\mathrm{p} 53$ protein and human papillomavirus in anogenital squamous lesions. Hum Pathol 1993;24:1238-42.

23 Cooper K, Herrington CS, Evans MF, Gatter KC, McGee JO'D. p53 expression in cervical condyloma, intraepithelial neoplasia and carcinoma: relationship to HPV infection and integration. $\mathcal{F}$ Pathol 1993;1 11:27-34.

24 Barry-Walsh C, Cassidy M, Younis F, Whelan D, Prendiville W, Leader M. Detection of c-erbB-2 and p53 expression in archival specimens of cervical intraepithelial neoplasia. F Pathol 1993;169(Suppl): 19.

25 Pollanen R, Soini Y, Vahakangas K, Paakko P, Lehto VP. Aberrant p53 protein expression in cervical intraepithelial neoplasia. Histopathology 1993;23:471-4.

26 Soini Y, Vahakangus K, Nuorva K, Kamel D, Lane DP, Paako P. p53 immunohistochemistry in malignant fibrous histiocytoma and other mesenchymal tumours. fibrous histiocytoma and

27 Helland A, Holm R, Kristensen G, Kaern J, Karlsen F, Trope C, et al. Genetic alterations of the TP53 gene, p53 protein expression and HPV infection in primary cervical carcinomas. F Pathol 1993;171:105-14.

28 Cattoretti G, Pileri S, Parravicini C, Becker MHG, Poggi S, Bifulco C, et al. Antigen unmasking on formalin-fixed paraffin-embedded tissue sections. I Pathol 1993;171: 83-98.

29 Norton AJ. Microwave oven heating for antigen unmasking in routinely processed tissue sections. $f$ Pathol 1993;171:79-80.

$30 \mathrm{McKee}$ PH, Hobbs C, Hall PA. Antigen retrieval by microwave irradiation lowers immunohistological detection thresholds. Histopathology 1993;23:377-9.

31 Campani D, Cecchetti D. Immunocytochemical p53 detection by microwave oven heating of routinely formalin-fixed paraffin sections. $\mathcal{F}$ Pathol 1993;171:151-2.

32 Bergeron C, Barrasso $R$, Beaudenon $S$, Flamant $P$, Croissant C, Orth G. Human papillomaviruses associated with cervical intraepithelial neoplasia. Am f Surg Pathol 1992;16:641-9. 